\title{
FACTORS THAT INFLUENGE THE ADOPTION OF THE INTERNET OF THINGS IN TOURISM BY ROMANIAN CONSUMERS
}

\author{
Vasile Dinu', Sorin Paul Lazăr ${ }^{2 *}$ and Iustin Atanasiu Pop ${ }^{3}$ \\ ${ }^{1)}$ Bucharest University of Economic Studies, Romania \\ Bucharest University of Economic Studies; Academy of Romanian Scientists \\ ${ }^{233)}$ Babeș-Bolyai University of Cluj-Napoca, Romania
}

Please cite this article as:

Dinu, V., Lazăr, S.P. and Pop, I.A., 2021. Factors That Influence the Adoption of the Internet of Things in Tourism by Romanian Consumers. Amfiteatru Economic, 23(57), pp.360-375.

\section{Article History}

Received: 17 December 2020

Revised: 13 February 2021

Accepted: 31 March 2021

DOI: $10.24818 / \mathrm{EA} / 2021 / 57 / 360$

\begin{abstract}
The study examines the causal relationship between the level of IoT adoption in tourism services and trust in these systems, on the one hand, and individual internal consumer behaviours, on the other. Influencing factors are grouped into six categories: awareness, confidentiality and safety, cost, convenience, social influence, and habits. Each category is described by several items, and the correctness of their aggregation is tested with the Cronbach's alpha coefficient. The dependent variable is defined on an ordinal scale, to be able to progressively evaluate the degree of IoT adoption. The research methodology uses the ordered multinomial logit model, applied to a database of 431 tourists from Romania. The main results show the significant influence of behavioural variables related to awareness, convenience, habits, and cost. Among the socio-demographic factors, the role of age and education was highlighted. The conclusions of the study make policy recommendations necessary for the development of IoT systems in tourism industry.
\end{abstract}

Keywords: IoT, tourism, ordered logit model, TAM model

JEL Classification: G22, C21

* Corresponding author, Sorin Paul Lazăr - e-mail: paul.lazar@ubbcluj.ro

Authors' ORCID:

Vasile Dinu: orcid.org/0000-0003-3606-2548

Sorin Paul Lazăr: orcid.org/0000-0003-0775-9231

Iustin Atanasiu Pop: orcid.org/0000-0002-6687-3109 


\section{Introduction}

In a broad sense, IoT (Internet of Things) is a system of intelligent technologies, connected to each other, which can communicate and transfer data over a network, based on defined algorithms, without the need for the intervention of a human entity.

Examples of such systems exist in various fields. In the medical sector there are people equipped with smart chips or a heart activity monitor that communicates directly with a cardiology clinic. Medical centres also use interconnected intelligent systems to better organize the management of medicines and medical equipment. In the automotive industry there are cars equipped with sensors that can communicate information to the driver or directly to a car service. Some insurance companies equip the insured cars with telemetry devices that calculate and communicate the route travelled, speed, violations of road regulations. Based on these data, the insurance premiums can be established more correctly and efficiently, avoiding the problems related to self-selectivity and adverse selection. Even in agriculture, some animals are equipped with chips that transmit data on position, health or other useful information to computers run by the owner, veterinarian, or public authorities. In plant culture, IoT-based management systems are used to regulate plant growth and development conditions, using air or soil sensors that transmit useful data for automatic irrigation systems. IoT systems are also used in public safety, through automatic traffic control systems or the identification of optimal routes in terms of time, cost or distance. In the field of housing (Bodea, Purnus,, 2018), there are smart homes, and the equipment varies from simple ones such as the thermostat for the central heating to more sophisticated devices that manage lighting and heating remotely through smart phones. The use of IoT systems is constantly evolving in various economic sectors so that companies can operate more efficiently, to know customers better and adapt to their needs, to make more accurate decisions and consequently to make more profitable business.

IoT is a system of devices equipped with artificial intelligence, connected in its own or public network (Nekit, Kolodin, Fedorov, 2020). The devices used are very diverse: chips, sensors, computers, processors, communication equipment, etc. They take over, process, synthesize, share, and transmit data from the environments in which they act. The processing of some data takes place locally, where it was collected, and the processing of other data takes place in a common space (cloud). Most processes take place directly between devices, without human intervention. Data collection, communication and analysis are automatic, but previously established by some protocols and algorithms.

The use of IoT systems can bring multiple benefits to companies, some being specific to a sector of activity, others being universal. Interconnected intelligent systems can monitor production processes, transportation, customer relationships and work relationships between employees. Business models established by corporate management can be more easily implemented and adapted. Instead, there may be disadvantages of IoT systems. As the amount of information accumulated in a system increases, the probability of a hacker being tempted by confidential information increases. Also, the amount of data becomes available raises major challenges regarding storage and processing, requiring a more professional management in terms of data analysis methods and programming of components equipped with artificial intelligence.

The tourism industry has recently benefited more and more from IoT systems. The applications are very varied. In some developed countries there are intelligent trains 
equipped with artificial intelligence systems that perform several functions: passenger information, train control through autonomous systems or WiFi networks, predictive maintenance, traffic signalling and monitoring, consumption efficiency (Verma and Shukla, 2019). In the hotel industry, IoT facilities are used for custom rooms, repair and predictive maintenance of hotel room facilities or electronic cards sent to the smartphone to avoid wasting time at the hotel reception (Martijn, 2018). The client's health can be monitored through sensors and can be communicated if necessary, to a clinic (Diachuk, 2018). Soon, the rooms of Marriot hotels will be equipped with mirrors with smart screen functions, lights and temperature will be adjusted by ordering from the smartphone, the shower will adjust the water temperature according to guests' requirements, and any malfunctions will be reported to staff. Smart parking and remote control for the pool will be used (McMullen, 2017). Tourist attractions also benefit from the recent implementation of IoT systems that can allow monitoring of attractions inside museums and visitor reactions by analysing data and sensors. Travel booking websites also have intelligent algorithms that allow customization of customer preferences. Using the user's IP address and other equipment associated with it, personalized offers are sent. The data processing algorithms follow the profile of the potential client by monitoring the internet searches related to tourism and considering the profile of previous reservations. According to Angelova (2017), the use of IoT in tourism has advantages and disadvantages. The main advantages are communication control, automation, enhanced experience, higher revenue, and cost saving. The disadvantages are the dangers related to data risk (security, protection, quality, accurate analysis, and compatibility) and confidentiality issues (lack of standards, protocols, interoperability, and legal issues).

Numerous academic studies explore various aspects of IoT systems. They focus mainly on system design issues, protocols and security, confidentiality, data risk, data analysis methods and economic effects. The literature on the effects of IoT systems on consumer behaviour is still very poor. The main objective of our study is to fill part of this gap, investigating the behavioural and socio-demographic influencing factors of consumer adoption of IoT usage results in accommodation reservation systems. The article is organized as follows. In the Review of the scientific Literature section, academic studies on IoT are reviewed, starting from general aspects, and converging to specific aspects related to the approval and use by consumers of such systems. The Methodology of Research section describes the consumer database, the variables and items used and how to use the multinomial logit model in the regressions that model the causal relationships. The Results and Discussions focus on the main trends emerging from the regression analysis and on the comparison with similar results obtained in other fields. The Conclusions summarize the study and focus on the recommendations that can be made because of the study results.

\section{Review of the scientific literature}

IoT systems are becoming more widespread in various aspects of human activities. The trend has been taken over by the academic literature, which is increasingly concerned with this topic. However, most articles refer to technical aspects of these systems: programming algorithms, technical reliability, communication protocols, design, development, implementation, and maintenance of high quality IoT systems. Very precise technical issues are being researched, such as: the impact of 5G technology on interconnected artificial intelligence ( $\mathrm{Li}, \mathrm{Da} \mathrm{Xu}$ and Zhao, 2018), security and cybercrime (Conti et al., 
2018), middleware models (da Cruz et al., 2018), machine learning adaptive algorithms for data processing (Mahdavinejad et al., 2018) or specific processing methodologies for big data (Ahmed et al., 2017).

However, studies that explore the effects on human society, both on those who manipulate these systems and on consumers, are beginning to appear very recently. Following a survey among experts working in this field, Reggio et al. (2020) show that the most relevant quality attributes for IoT systems are reliability, availability, performance, scalability, and security. Researchers are also analysing the advantages and disadvantages of radical change in modern society because of IoT development. According to economists, the main disadvantage is the loss of many jobs. A comparative study by empirical evidence of the advantages and disadvantages of Japanese, German, and Australian societies is conducted by Shenkoya (2020). The results show that IoT improves research funding and the efficiency of business processes, while increasing job creation. The impact on human society is also analysed by Nižetić et al (2020). Four main current areas are discussed: energy and sustainable environment, smart hats, E-health - environmentally assisted living systems and technologies in transport and low-carbon products. The environmental implications of the increased application of IoT products are discussed. Research on the implementation of interconnected smart systems in the field of business is also of increasing interest. A global perspective of IoT deployment in a business is presented by Lee (2019) which presents an IoT ecosystem, an IoT architecture and a business model of IoT services, essential for the selection and implementation of IoT services in different enterprise settings. It also exemplifies how IoT services can be developed to innovate hotel rooms. Nitti et al. (2017) define an architectural structure for a sustainable tourism application in a smart city. The idea of developing smart tourist destinations through IoT is addressed by Wise and Heidari (2019). They show that smart technology that exploits IoT data offers new opportunities for the tourism industry, allowing easy access and interaction with a wide variety of information for transportation, attractions, tours, shopping, and hotels. Smart tourism is approached by Kaur and Kaur (2016) which offers a perspective on this concept and how it can be achieved through modern IoT technology. It requires the collaboration of participants in the tourism industry through a common technology platform and provides an algorithm for cooperative operation through the exchange, processing, and analysis of information.

As we can see, the academic literature covers various aspects related to IoT systems: technical aspects related to design, protocols, security, data processing algorithms, but also some effects on society, economy, and business. However, the literature on investigating the influencing factors of consumer adoption of IoT systems is much poorer. Theories that come from consumer behaviour stipulate that there are two essential conditions for accepting a technology: its usefulness and ease of use, as stated (Davis, 1989; de Boer, van Deursen and van Rompay, 2019) on the Technology Acceptance Model (TAM ). The TAM model was later used in various applications, such as factors affecting the intention to use an online learning community (Liu et al., 2010), clinical information systems among hospital medical staff (Melas et al., 2011) or mobile banking applications (Munoz-Leiva, Climent-Climent and Liébana-Cabanillas, 2017; Almugari et al., 2019). Other factors influencing IoT adoption are convenience, social influence, habits, privacy, safety, awareness, and costs (Almugari et al., 2019). Convenience as a factor of influence is found especially in marketing, generally with the sense of saving time and buying time (Cho and Sagynov, 2015). Previous studies have subsequently confirmed that ease of use significantly

Vol. $23 \cdot$ No. $57 \cdot$ May 2021 
determines the intention of behavior towards the adoption of new technologies (Del Giudice et al., 2016). An equally important factor in accepting new intelligent systems is social influence (Aldossari and Sidorova, 2018). The influence of family, friends, colleagues, and the media can influence the intention of consumers to adopt IoT products and services of banks (Almugari et al., 2019). Habits have also been identified as a significant factor in the adoption of digital technologies (Alalwan et al., 2015). Abushakra and Nikbin (2019) also found an important strong relationship between habits and IoT adoption. The stated determinants are found in many consumer-oriented marketing studies. They appear in various forms in market research and as questions in questionnaires on purchase intentions for all types of products. Instead, there are specific factors related to the adoption of technologies in general and the IoT in particular: safety and privacy. The peculiarity lies in the fact that artificial intelligence systems operate with data that consumers do not want to make public. These determinants have been shown to be significant in empirical studies (Axelrod, 2015; Atlam and Wills, 2020). Consumers may be concerned that digital service providers may use personal information for the benefit of the company or collect personal data without customer permission. Consequently, there may be negative effects on IoT service demand. Another component of the TAM model is the awareness and understanding of how to use the new technology. The Internet of Things is a new phenomenon for a large part of consumers of tourism products, because of which service providers are interested in making them aware of new technologies. Awareness as a factor in technology adoption has been explored for IoT systems in general (Guo et al., 2013; Gite and Agrawal, 2016), but there are also some studies that address specific sectors, such as banking (Almugari et al., 2019). Cost is a factor with more general coverage, not necessarily specific to the TAM model. It is found as a determinant in most empirical studies on demand for a particular product or service. Sometimes it is viewed in a narrow sense, referring to the price of providing the product or service (Tehranipoor et al., 2018; McPherson and Irvine, 2020). Sometimes it is considered in a broader sense, including collateral costs (lost time Almugari et al., 2019). In addition to the components of the TAM model, interesting correlations can be identified with some socio-demographic variables such as age, sex, income, level of education or marital status. However, there are few studies (eg.: Gunasekara and Fernando, 2017) that link the adoption of IoT to such indicators.

\section{Research methodology}

To evaluate the importance of the determinants of the adoption of the tourist services provided with the help of IoT systems, we use an econometric model with discrete regressions. The level of consumer adoption of the services provided is measured in our study by the ordinal variable ADOPTION (see the paragraph on regression variables and table 1 for the complete definition of the variable). Ordinal scaling allows the identification of variables that increase the probability of situating at higher levels the adoption of IoT technology. For statistical estimates we use Ordered Logit Model with the following structure:

$$
\begin{aligned}
& \operatorname{Prob}\left(y_{i}=j \mid x, b, c\right)=F\left(c_{j+1}-x_{i} b\right)-F\left(c_{j}-x_{i} b\right) \\
& \operatorname{Prob}\left(y_{i}=j \mid x, b, c\right)=\frac{\exp \left(c_{j+1}-x_{i} b\right)}{1+\exp \left(c_{j+1}-x_{i} b\right)}-\frac{\exp \left(c_{j}-x_{i} b\right)}{1+\exp \left(c_{j}-x_{i} b\right)}
\end{aligned}
$$


$i=\overline{1, N}$ index the consumers in the sample

$j=\overline{1,3}$ indexes the three alternatives of the endogenous variable (ADOPTION)

$x_{i}$ is the vector of explanatory variables (CONV, SOC_INLF, HABITS, PRIV_SAFE, AWAR, COST, GENDER, MARRIED, AGE, EDUC, RESID)

$b$ is the vector of regression coefficients

$c_{j}, j=0,1,2,3$ are cutoffs of the distribution (technical coefficients of the model)

$c_{0}=-\infty, c_{3}=\infty$

$c_{1}$ and $c_{2}$ are estimated by the maximum likelihood method.

The model is also controlled for heteroskedasticity by Davidson and MacKinnon's (1984) test, based on the Lagrange multiplier (LM) principle. The coefficients reported in the regression are robust, corrected for heteroskedasticity. The robustness of the prediction is verified by the Receiver Operating Characteristics curve developed for multinomial models (Dragos, 2010).

Following the study of the literature, using the data and methodology described above, we formulate the following research hypothesis: the level of adoption by Romanian consumers of IoT technologies in tourism is influenced by TAM model components: convenience, social influence, habits, confidentiality and safety, awareness, and costs.

\section{Data}

The data are collected by sampling between August and September 2020 using the CATI (Computer-Assisted Telephonic Interview) method. To avoid as much as possible, the biases of the values of the variables, the personal numerical code was used as an identification element, which allows a stratified and proportional survey in relation to the geographical area, gender, and age. The survey is balanced at national level, there are between 8 and 15 respondents from each county, proportional to the number of inhabitants. The survey is conducted nationwide, finally comprising 431 respondents who provided complete data on the questions in the sample. A part of the Romanian population, especially elderly people from the rural area do not go on vacation and as a result they could not answer the questions, so they were excluded from the sample. This elimination caused some biases of the average values of the socio-demographic factors in relation to the national values (see Table no. 1).

\section{Variables}

The endogenous variable ADOPTION ( $\mathrm{Y}$ in the theoretical model) is a proxy that measures on an ordinal scale from 1 to 3 the level of use of services provided by IoT systems in tourism. Special offers offered by online accommodation booking websites are especially considered. They collect information about the potential consumer following the specifics 
of his internet searches regarding the type of destination (sea, mountain, city, spa), the profile of the accommodation units pursued (hotel, pension, holiday home), etc. As a result of running artificial intelligence algorithms, tourist destinations or accommodation units are proposed through alert systems on the smartphone, tablet, or computer. The variable ADOPTION follows on an ordinal scale how often tourists use the destinations and accommodations proposed by IoT systems. The variable takes the value 1 if the individual never uses services provided by IoT in tourism; value 2 if he rarely uses such services and value 3 if he uses it regularly. The explanations regarding such mechanisms for proposing offers through IoT systems in tourism are explained to the people in the sample during the interview. The results regarding the answers are summarized in table no. 1.

Table no. 1. Variables used in analysis and descriptive statistics: mean, standard deviation, minimum and maximum value

\begin{tabular}{|c|c|c|c|c|c|}
\hline Variable & Explanations & Mean & St. Dev. & Min & Max \\
\hline ADOPTION & $\begin{array}{l}\text { Adoption of services provided through IoT } \\
\text { systems in tourism. Measured ordinarily, on a } \\
\text { scale from } 1 \text { to } 3 \text { in ascending order of degree of } \\
\text { adoption. }\end{array}$ & 0.93 & 0.74 & 1 & 3 \\
\hline CONV & $\begin{array}{l}\text { Convenience. Measured quantitatively, as an } \\
\text { average of } 3 \text { ordinal items: SAVING_TIME, } \\
\text { AVOID_MOV and ELAST_TIME (complete } \\
\text { description of the items in the Appendix no. 1). }\end{array}$ & 3.55 & 0.92 & 1 & 5 \\
\hline SOC_INFL & $\begin{array}{l}\text { Social influence. Measured quantitatively, as an } \\
\text { average of } 3 \text { ordinal items: FRQ_ENTOUR, } \\
\text { REC_ENTOUR and PUB_AUTH (complete } \\
\text { description of the items in the Appendix no. 2). }\end{array}$ & 2.80 & 0.82 & 1 & 4.67 \\
\hline HABITS & $\begin{array}{l}\text { Habits regarding the use of IoT and other digital } \\
\text { systems. Measured quantitatively, as an average } \\
\text { of } 3 \text { ordinal items: FRQ_PROF, FREE_TIME } \\
\text { and DIGITAL (complete description of the } \\
\text { items in the Appendix no. 3). }\end{array}$ & 3.05 & 0.99 & 1 & 5 \\
\hline PRIV_SAFE & $\begin{array}{l}\text { Privacy and safety. Measured quantitatively, as } \\
\text { an average of } 3 \text { ordinal items: } \\
\text { RISK_PRODUCT, PRIV_DATA and } \\
\text { RISK_UNSUCC (complete description of the } \\
\text { items in the Appendix no. 4). }\end{array}$ & 2.74 & 0.85 & 1 & 4.67 \\
\hline AWAR & $\begin{array}{l}\text { Awareness. Measured quantitatively, as an } \\
\text { average of } 3 \text { ordinal items: ADV_IOT, } \\
\text { DISADV_IOT and OTHER_EXP (complete } \\
\text { description of the items in the Appendix no. 5). }\end{array}$ & 2.87 & 1.08 & 1 & 5 \\
\hline COST & $\begin{array}{l}\text { Costs - the importance of the best price and the } \\
\text { confidence that it is identified by IoT systems. } \\
\text { Measured quantitatively, as an average of } 2 \\
\text { ordinal items: IMP_PRICE and } \\
\text { IDENT_PRICE (full description of the items in } \\
\text { the Appendix no. 6). }\end{array}$ & 3.52 & 0.95 & 1 & 5 \\
\hline GENDER & Gender ( 1 if male, 0 if female). & 0.51 & 0.50 & 0 & 1 \\
\hline MARRIED & $\begin{array}{l}\text { Marital status ( } 1 \text { if the consumer is married or in } \\
\text { a long-term relationship, } 0 \text { if he is unmarried, } \\
\text { alone). }\end{array}$ & 0.74 & 0.44 & 0 & 1 \\
\hline AGE & Age of the consumer (years). & 45.3 & 12.0 & 18 & 66 \\
\hline
\end{tabular}




\begin{tabular}{|l|l|c|c|c|c|}
\hline Variable & Explanations & Mean & St. Dev. & Min & Max \\
\hline EDUC & $\begin{array}{l}\text { The level of the highest education institution } \\
\text { graduated (1 if he has graduated only primary or } \\
\text { secondary school, 2 if he graduated high school } \\
\text { or vocational school, 3 if he has university or } \\
\text { postgraduate studies). }\end{array}$ & 2.27 & 0.71 & 1 & 3 \\
\hline RESID & Residential area (1 if urban, 0 if rural) & 0.64 & 0.48 & 0 & 1 \\
\hline
\end{tabular}

Note: St. Dev. = standard deviation

To better measure as many aspects of the determinants that come from the TAM model, each explanatory variable is defined based on several component items. The items are not included in the regressions, because within each category (convenience, social influence, etc.) they are very correlated with each other and would have posed problems of multicollinearity. In addition, considering each of them as an explanatory variable would have made the econometric model less representative by considerably reducing the ratio between the number of observations and the number of explanatory variables. However, the information contained in the items is found in the regressions by aggregating them to form variables, one for each component of the TAM model (CONV, SOC_INLF, HABITS, PRIV_SAFE, AWAR, COST).

Table no. 2 only briefly presents the items that make up the variables, to be easily identified in the presentation of the study results. Their more complete description, as they come from the questions of the questionnaire is given in Annexes no. 1, 2, 3, 4, 5 and 6.

Table no. 2. Brief information on the items that make up the explanatory variables

\begin{tabular}{|l|l|l|r|r|}
\hline \multirow{2}{*}{ Variable } & Item coding & $\begin{array}{l}\text { The meaning of the item. All items } \\
\text { are scaled up from 1 to 5 }\end{array}$ & Median & $\begin{array}{c}\text { St. } \\
\text { Dev. }\end{array}$ \\
\hline \multirow{4}{*}{ CONV } & SAVING_TIME & Saving time & 3.69 & 2.32 \\
\cline { 2 - 5 } & AVOID_MOV & Avoiding movement & 3.43 & 2.32 \\
\cline { 2 - 5 } & ELAST_TIME & Elasticity of time & 3.93 & 2.38 \\
\hline \multirow{4}{*}{ SOCIAL } & FRQ_ENTOUR & Entourage frequency & 3.04 & 2.51 \\
\cline { 2 - 5 } & REC_ENTOUR & Entourage recommendations & 3.33 & 2.40 \\
\cline { 2 - 5 } & PUB_AUTH & Public authorities & 2.71 & 2.48 \\
\hline \multirow{4}{*}{ PRIV_SAFE } & FRQ_PROF & Professional IoT frequency & 2.94 & 2.35 \\
\cline { 2 - 5 } & FREE_TIME & IoT in your free time & 3.23 & 2.32 \\
\cline { 2 - 5 } & DIGITAL & Use of digital technologies & 3.53 & 2.29 \\
\cline { 2 - 5 } & RISK_PRODUCT & Product risk & 3.28 & 2.43 \\
\cline { 2 - 5 } & RISK_UATS & Privacy of data & 2.62 & 2.49 \\
\hline \multirow{3}{*}{ AWARENESS } & ADV_IOT & Risk of unsuccessful vacation & 2.96 & 2.38 \\
\cline { 2 - 5 } & DISADV_IOT & Awareness of IoT benefits & 2.09 & 2.31 \\
\cline { 2 - 5 } & OTHER_EXP & Knowing the experiences of others & 3.42 & 2.38 \\
\hline \multirow{2}{*}{ COST } & IMP_PRICE & The importance of the best price & 4.27 & 2.29 \\
\cline { 2 - 5 } & IDENT_PRICE & Optimal price identification via IoT & 3.39 & 2.32 \\
\hline
\end{tabular}

Note: St. Dev. = standard deviation

\section{Results and discussions}

In many cases where the data come from the questions of a questionnaire, the problem of variability of the values of some items can be raised. If a pre-test of the questionnaire was not used, for some questions there can be mostly only negative or positive answers. 
For example, on a Likert scale from 1 to 5 we can have exaggeratedly large proportions of answers 1 or 5 . The effects on regression can be very serious in these cases, practically trying to identify correlations between an endogenous variable and a constant. In such a situation, even if the phenomenon exists, it being poorly measured, the results are degraded. In our study, because of pretesting the sample, some questions were recalibrated. Consequently, there is a good variability of the answers for all the items used, even if some distributions are asymmetric (Figure no. 1).

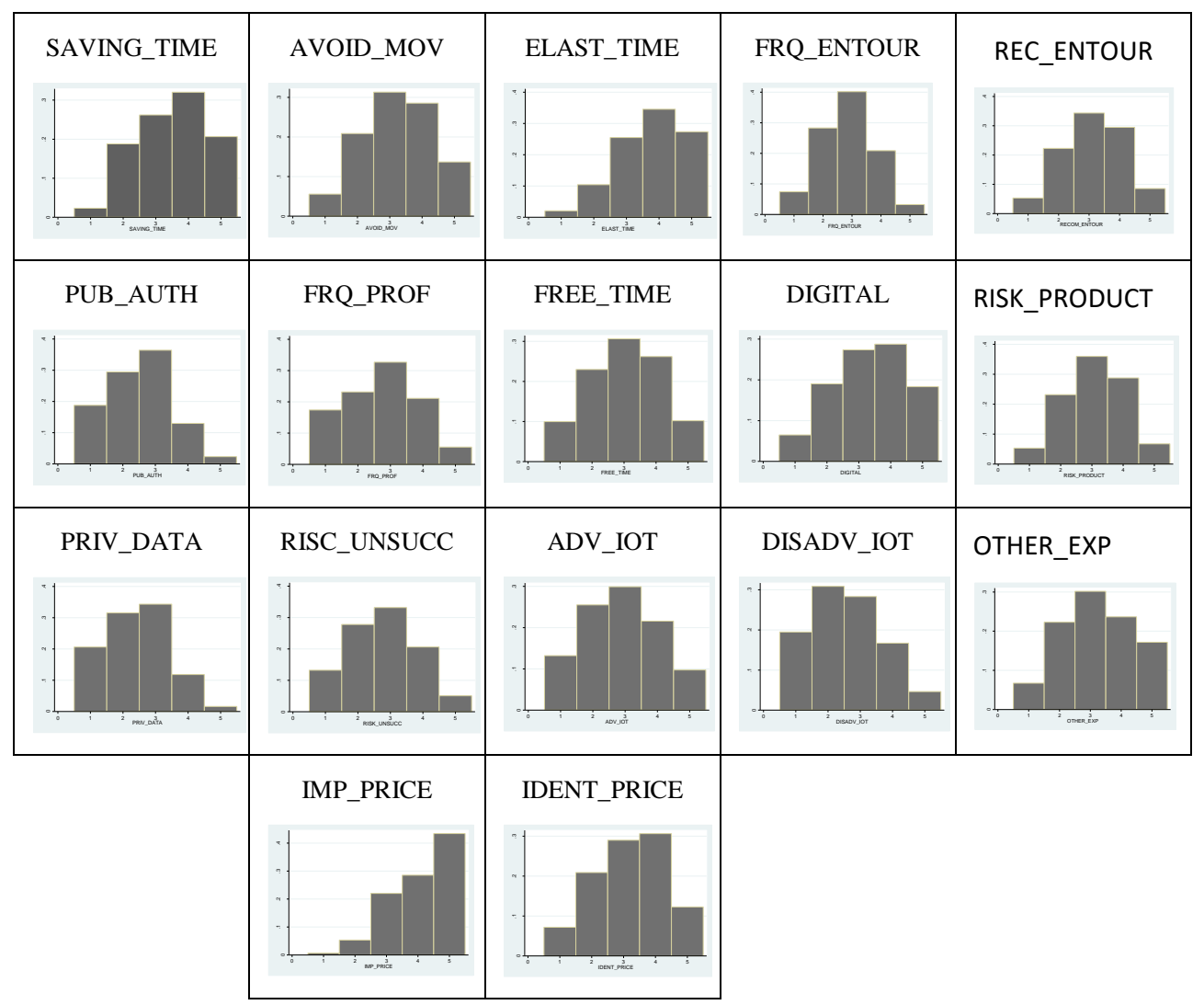

Figure no. 1. Distribution of answers for items

To measure the reliability of variable aggregation and to verify the extent to which all items that make up a variable measure the same concept, we calculate Cronbach's alpha coefficient (Cronbach, 1951). The alpha coefficients calculated for the items in our database are between 0.776 and 0.871 (Table no. 3), which indicates a robust result (McNeish, 2018).

Table no. 3. Reliability of item aggregation - Cronbach's alpha

\begin{tabular}{|l|c|c|c|c|c|c|}
\hline Variable & CONV & SOC_INFL & HABITS & PRIV_SAFE & AWAR & COST \\
\hline $\begin{array}{l}\text { Average interitem } \\
\text { covariance }\end{array}$ & 0.754 & 0.644 & 0.890 & 0.658 & 0.723 & 0.692 \\
\hline $\begin{array}{l}\text { Reliability } \\
\text { coefficient (a) }\end{array}$ & 0.850 & 0.847 & 0.861 & 0.833 & 0.871 & 0.776 \\
\hline
\end{tabular}


The results of the ordinal logistic regression (Table no. 4) are obtained after the correction for heteroskedasticity (Davidson and MacKinnon, 1984), so with a robust estimator for the standard error and consequently for the probability of rejecting the significance of the regression coefficients.

Table no. 4. The effects of influencing factors on IoT adoption in tourism; robust estimates of the ordered logit model; endogenous variable ADOPTION

\begin{tabular}{|l|c|c|c|c|}
\hline & $\begin{array}{c}\text { Regression } \\
\text { coefficient }\end{array}$ & $\begin{array}{c}\text { Standard error, } \\
\text { robust estimation }\end{array}$ & $\boldsymbol{p}$ - value & Significance \\
\hline CONV & 0.291 & 0.106 & 0.006 & $* * *$ \\
\hline SOCIAL & 0.192 & 0.125 & 0.123 & \\
\hline HABITS & 0.199 & 0.098 & 0.043 & $* *$ \\
\hline PRIV_SAFE & -0.054 & 0.111 & 0.627 & \\
\hline AWARENESS & 0.179 & 0.093 & 0.055 & $*$ \\
\hline COST & 0.374 & 0.098 & 0.000 & $* * *$ \\
\hline GENDER & 0.171 & 0.193 & 0.376 & \\
\hline MARRIED & -0.248 & 0.213 & 0.246 & \\
\hline AGE & -0.018 & 0.008 & 0.027 & $* *$ \\
\hline EDUC & 0.282 & 0.136 & 0.037 & $* *$ \\
\hline RESID & 0.035 & 0.197 & 0.859 & \\
\hline
\end{tabular}

Note: ***,**, : significant at $1 \%, 5 \%$ and $10 \%$ level

We observe first that the CONV variable has a statistically significant positive influence $(\mathrm{p}=0.006)$ on the adoption of the services provided through IoT. The convenience offered by the lack of the need to move to a travel agency to find suitable offers seems to be conclusive. Also, the elasticity of time is part of this variable, the possibility to consult the offers in $24 / 7$ regime is very attractive. Social influence is instead insignificant $(p=0.123)$. The result can be explained by the fact that the influence of the entourage risks being less decisive than in other activities. In tourism in general and in the choice of destinations in particular, the preferences are very heterogeneous and the fact that people around us recommend something to us might prove inappropriate for our preferences. In addition, the public authorities do not encourage much in Romania the use of digital systems in relation to the state authorities, as a result there is not a sufficiently important social stimulus for the use of IoT systems. Habits (HABITS variable) are statistically significant $(\mathrm{p}=0.043$ ). People who use IoT more frequently in their professional lives, but also in leisure activities (eg looking for a parking space available through online systems) are more likely to adopt more frequent tourist services offered by interconnected artificial intelligence. The habit of using digital technology of any kind (eg various applications for smartphones) probably also has a beneficial role in habits. The elements of confidentiality and security (variable PRIV_SAFE) do not appear to be significant $(\mathrm{p}=0.627)$. The result is in contradiction with the study of Munoz-Leiva, Climent-Climent and Liébana-Cabanillas (2017) on the adoption of IoT banking by Indian consumers. It seems that tourism customers do not have major concerns about the security of personal data and the confidentiality of information transmitted through such systems. Indeed, compared to the banking sector, where the data contain salaries and payments, the possible theft of information on internet searches regarding certain destinations is generally not worrying. Nor does the risk of failing a vacation, or another service that meets expectations, seem to have a major impact. Indeed, 
with the development of IoT systems there is an essential element of controlling these risks through the large number of online reviews and recommendations from other consumers. A positive influence with lower significance $(\mathrm{p}=0.055)$ has awareness (variable AWARENESS). This is partly explained by the knowledge to a lesser extent by the population of the advantages and especially of the disadvantages of using IoT in tourism (the average value of the DISADV_IOT item is equal to 2.76). Instead, consumers are better acquainted with other people's experiences (the average value of the OTHER_EXP item is 3.42), which is encouraging, proving that the population is trying to inform itself and offers a favourable perspective for the development of IoT systems in the future. Romanian consumers of tourist services seem to be the most sensitive $(p<0.001)$ to costs (variable COST). This result is also in contradiction with studies on the banking services market (Almugari et al., 2019), where the cost is insignificant, the most decisive for the adoption of services being convenience and awareness. In fact, of all the items from the questionnaire, the importance of the price (IMP_PRICE item) had the highest average value, of 4.27. Among the socio-demographic variables are significant age (AGE variable, $p=0.027$ ) and education (EDUC variable, $p=0.037$ ). The signs of the coefficients are the expected ones, the younger and more educated people having a higher probability of frequent use of IoT systems in tourism. Gender and marital status do not have a significant impact. The RESID variable is not significant at all $(\mathrm{p}=0.089)$, its effect being probably taken over by education, in rural areas there is a much lower percentage of people with higher education than in urban areas.

\section{Conclusion}

The issue of IoT systems is relatively recent in the literature but is currently an important topic. Most studies refer to technical aspects: programming algorithms, technical reliability, communication protocols, design, development, implementation, and maintenance of high quality IoT systems. Concerns about the effects on human society have gradually developed, discussing the advantages and disadvantages of radical change in modern society because of the development of interconnected artificial intelligence systems. The fields of study are diverse: energy and sustainable environment, smart hats, E-health environmentally assisted living systems, transport technologies, low carbon products, etc.

However, the effects on consumers have been much less explored. Specialists turned rather to the effect of applications in the banking system. Our study aims to fill a gap in the literature, highlighting specific determinants of IoT adoption in tourism in general and in reservation systems. Econometric estimates indicate the significant influence of behavioural variables related to awareness, convenience, habits, and cost. There are notable differences from the banking system, where social influence, confidentiality and security of transactions are decisive. Among the socio-demographic factors, the role of age and education was highlighted, the younger and more educated people having higher probabilities of frequent use of the tourist services proposed by IoT systems.

The mechanisms highlighted by this study can be used to better match demand with supply. By observing the frequency of use and the type of service chosen or not by consumers, IoT system programmers can adapt algorithms to select relevant information on consumer behavior in relation to the type of tourist offers. Thus, the offers that are rarely purchased by tourists, come from defective algorithms, which must be corrected. Public authorities 
may find that a major impediment to increasing the frequency of IoT use is the poor development of these systems in relations between state institutions and citizens. Because there is no correlation between the frequency of IoT use and privacy and data security issues, it means that consumers are not seriously concerned about these issues in tourism. Consequently, such data necessary for the optimal configuration of the offers can be collected, of course in compliance with the legislative framework.

\section{References}

Abushakra, A. and Nikbin, D., 2019. Extending the UTAUT2 model to understand the entrepreneur acceptance and adopting Internet of Things (IoT). In: L. Uden, I.-H. Ting and J.M. Corchado, eds. 2019. Knowledge Management in Organizations. Cham: Springer, pp. 339-347. DOI: 10.1007/978-3-030-21451-7_29

Ahmed, E., Yaqoob, I., Hashem, I. A. T., Khan, I., Ahmed, A. I. A., Imran, M. and Vasilakos, A. V., 2017. The role of big data analytics in Internet of Things. Computer Networks, 129, pp. 459-471. DOI: 10.1016/j.comnet.2017.06.013

Alalwan, A. A., Dwivedi, Y. K., Rana, N. P., Lal, B. and Williams, M. D. (2015). Consumer adoption of Internet banking în Jordan: Examining the role of hedonic motivation, habit, self-efficacy and trust. Journal of Financial Services Marketing, 20(2), pp. 145-157. DOI: 10.1057/fsm.2015.5

Aldossari, M. Q. and Sidorova, A., 2020. Consumer acceptance of Internet of Things (IoT): Smart home context. Journal of Computer Information Systems, 60(6), pp. 1-11. DOI: 10.1080/08874417.2018.1543000

Almugari, F., Bajaj, P., Tabash, M. I., Khan, A. and Ali, M. A., 2020. An examination of consumers' adoption of internet of things (IoT) in Indian banks. Cogent Business \& Management, 7(1). DOI: 10.1080/23311975.2020.1809071

Angelova, N., Kiryakova, G. and Yordanova, L., 2017. The great impact of internet of things on business. Trakia Journal of Sciences, 15(1), pp. 406-412. DOI: 10.15547/tjs.2017.s.01.068

Atlam, H. F. and Wills, G. B., 2020. IoT security, privacy, safety and ethics. In: M. Farsi, A. Daneshkhah, A. Hosseinian-Far and H. Jahankhani, eds. 2020. Digital Twin Technologies and Smart Cities. Cham: Springer, pp. 123-149.

Axelrod, C. W., 2015. Enforcing security, safety and privacy for the Internet of Things. In: s.n., 2015 Long Island Systems, Applications and Technology. Farmingdale, NY, USA, 1 May 2015. S.1: IEEE, pp. 1-6. DOI: 10.1109/LISAT.2015.7160214.

Bodea, C.-N., Purnuş, A., 2018. Legal implications of adopting Building Information Modeling (BIM). Juridical Tribune - Tribuna Juridica, 8(1), pp. 63-72.

Cho, Y. C. and Sagynov, E., 2015. Exploring factors that affect usefulness, ease of use, trust, and purchase intention in the online environment. International Journal of Management \& Information Systems (IJMIS), 19(1), pp. 21-36. DOI: 10.19030/ ijmis.v19i1.9086

Conti, M., Dehghantanha, A., Franke, K. and Watson, S., 2018. Internet of Things security and forensics: Challenges and opportunities. S.l.: Elsevier. DOI: 10.1016/ j.future.2017.07.060

Cronbach, L. J., 1951. Coefficient alpha and the internal structure of tests. Psychometrika, 16(3), pp. 297-334. DOI: 10.1007/BF02310555 
da Cruz, M. A., Rodrigues, J. J. P., Al-Muhtadi, J., Korotaev, V. V. and de Albuquerque, V. H. C., 2018. A reference model for internet of things middleware. IEEE Internet of Things Journal, 5(2), pp. 871-883. DOI: 10.1109/JIOT.2018.2796561

de Boer, P. S., van Deursen, A. J. and Van Rompay, T. J., 2019. Accepting the Internet-ofThings in our homes: The role of user skills. Telematics and informatics, 36(1), pp. 147-156. DOI: 10.1016/j.tele.2018.12.004

Davidson, R. and MacKinnon, J. G., 1984. Convenient specification tests for logit and probit models. Journal of Econometrics, 25(3), pp. 241-262. DOI: 10.1016/03044076(84)90001-0

Davis, F. D., 1989. Perceived usefulness, perceived ease of use, and user acceptance of information technology. MIS quarterly, 13(3), pp. 319-340. DOI: 10.2307/249008

Del Giudice, M., Campanella, F., Dezi, L. and Al-Mashari, M., 2016. The bank of things: An empirical investigation on the profitability of the financial services of the future. Business Process Management Journal, 22(2), pp. 324-340. DOI: 10.1108/BPMJ-102015-0139

Diachuk, M., 2018. Benefits of Using IoT in Healthcare - DZone IoT. [online] Available at: <https://dzone.com/articles/benefits-of-using-iot-in-healthcare> Accessed 11 November 2020].

Dragos, C., 2010. ROC curve for discrete choice models an application to the Romanian car market. Applied Economics Letters, 17(1), pp. 75-79. DOI: 10.1080/13504850701719793

Gite, S. and Agrawal, H., 2016. On context awareness for multisensor data fusion in IoT. In: S. C. Satapathy, K. S. Raju, J. K. Mandal and V. Bhateja, eds. 2016. Proceedings of the Second International Conference on Computer and Communication Technologies. New Delhi: Springer, pp. 85-93.

Gunasekara, M. A. N. P. and Fernando, M., 2017. Eradicating health communication inequalities in the internet of things era. In: s.n, 2017 International Conference on IoT and Application (ICIOT). Nagapattinam, India, 19-20 May 2017. S.1: IEEE, pp. 1-3. DOI: 10.1109/ICIOTA.2017.8073620

Guo, B., Zhang, D., Wang, Z., Yu, Z. and Zhou, X., 2013. Opportunistic IoT: Exploring the harmonious interaction between human and the internet of things. Journal of Network and Computer Applications, 36(6), pp. 1531-1539. DOI: 10.1016/j.jnca.2012.12.028

Kaur, K. and Kaur, R., 2016). Internet of things to promote tourism: An insight into smart tourism. International Journal of recent trends in engineering \& research, 2(4), pp. 357-361.

Lee, I., 2019. The Internet of Things for enterprises: An ecosystem, architecture, and IoT service business model. Internet of Things, 7: 100078. DOI: 10.1016/j.iot.2019.100078

Li, S., Da Xu, L. and Zhao, S., 2018. 5G Internet of Things: A survey. Journal of Industrial Information Integration, 10(1), pp. 1-9. DOI: 10.1016/j.jii.2018.01.005

Liu, I. F., Chen, M. C., Sun, Y. S., Wible, D. and Kuo, C. H., 2010. Extending the TAM model to explore the factors that affect Intention to Use an Online Learning Community. Computers \& education, 54(2), pp. 600-610. DOI: 10.1016/j.compedu.2009.09.009

Mahdavinejad, M. S., Rezvan, M., Barekatain, M., Adibi, P., Barnaghi, P. and Sheth, A. P., 2018. Machine learning for Internet of Things data analysis: A survey. Digital Communications and Networks, 4(3), pp. 161-175. DOI: 10.1016/j.dcan.2017.10.002 
Martijn, N., 2018. How the Internet of Things (IoT) can Benefit the Hospitality Industry. [online] Available at: <https://www.revfine.com/internet-of-things-hospitalityindustry/> [Accessed 11 November 2020].

Melas, C. D., Zampetakis, L. A., Dimopoulou, A. and Moustakis, V., 2011. Modeling the acceptance of clinical information systems among hospital medical staff: an extended TAM model. Journal of biomedical informatics, 44(4), pp. 553-564. DOI: 10.1016/ j.jbi.2011.01.009

McNeish, D., 2018. Thanks coefficient alpha, we'll take it from here. Psychological Methods, 23(3), pp. 412-427. DOI: 10.1037/met0000144

McPherson, R. and Irvine, J., 2020. Using smartphones to enable low-cost secure consumer IoT devices. IEEE Access, 8, pp. 28607-28613. DOI: 10.1109/ACCESS.2020.2968627

Munoz-Leiva, F., Climent-Climent, S. and Liébana-Cabanillas, F., 2017. Determinants of intention to use the mobile banking apps: An extension of the classic TAM model. Spanish Journal of Marketing-ESIC, 21(1), pp. 25-38. DOI: 10.1016/j.sjme.2016.12.001

Nekit, K., Kolodin, D., Fedorov, V., 2020. Personal data protection and liability for damage in the field of the internet of things. Juridical Tribune - Tribuna Juridica, 10(1), pp. 80-93.

Nižetić, S., Šolić, P., González-de, D. L. D. I. and Patrono, L., 2020. Internet of Things (IoT): Opportunities, issues and challenges towards a smart and sustainable future. Journal of Cleaner Production, 274, 122877. DOI: 10.1016/j.jclepro.2020.122877.

Nitti, M., Pilloni, V., Giusto, D. and Popescu, V., 2017. IoT Architecture for a sustainable tourism application in a smart city environment. Mobile Inf. Systems, 4(1), pp. 1-9. DOI: $10.1155 / 2017 / 9201640$.

Reggio, G., Leotta, M., Cerioli, M., Spalazzese, R. and Alkhabbas, F., 2020. What Are IoT Systems for Real? An Experts' Survey on Software Engineering Aspects. Internet of Things, in press. DOI: 10.1016/j.iot.2020.100313.

Shenkoya, T., 2020. Social change: A comparative analysis of the impact of the IoT in Japan, Germany and Australia. Internet of Things, 11, 100250. DOI: 10.1016/ j.iot.2020.100250.

Tehranipoor, F., Karimian, N., Wortman, P. A. and Chandy, J. A., 2018. Low-cost authentication paradigm for consumer electronics within the internet of wearable fitness tracking applications. In: s.n., 2018 IEEE International Conference on Consumer Electronics (ICCE). Las Vegas, NV, USA, 12-14 January 2018. S.1: IEEE, pp. 1-6. DOI: $10.1109 /$ ICCE.2018.8326233

Verma, A. and Shukla, V., 2019. Analyzing the influence of IoT in Tourism Industry. In: Amity University Rajasthan, International Conference on Sustainable Computing in Science, Technology and Management (SUSCOM). Jaipur, India, 26-28 February 2019. S.l:s.n.

Wise, N. and Heidari, H., 2019. Developing smart tourism destinations with the internet of things. In: M. Sigala, R. Rahimi and M. Thelwall, eds. 2019. Big Data and Innovation in Tourism, Travel, and Hospitality . Singapore: Springer, pp. 21-29. DOI: 10.1007/978981-13-6339-9_2 


\section{Annexes}

Annex no. 1. Items of the CONV variable and the distribution of answers

\begin{tabular}{|l|l|l|l|l|c|c|}
\hline Item & \multicolumn{3}{|l|}{$\begin{array}{l}\text { Explanations regarding the item. All items are } \\
\text { scaled up from 1 to 5 }\end{array}$} & \multicolumn{3}{|l|}{ Percentage of response options } \\
\cline { 2 - 6 } & $\begin{array}{l}\text { Saving time. The importance of saving time } \\
\text { Sy using IoT (not at all important to very } \\
\text { important). }\end{array}$ & 2.3 & 18.8 & 26.2 & 32.0 & 20.6 \\
\hline AVOID_MOV & $\begin{array}{l}\text { Avoiding movement. The importance of } \\
\text { avoiding the inconveniences of movement to } \\
\text { a travel agency: congestion, waiting times, the } \\
\text { possibility of meeting less pleasant people } \\
\text { (not at all important to very important). }\end{array}$ & 5.6 & 20.9 & 31.3 & 28.5 & 13.7 \\
\hline ELAST_TIME & $\begin{array}{l}\text { Elasticity of time. The importance of } \\
\text { elasticity given by the possibility of accessing } \\
\text { IoT services 24 hours a day and days a week } \\
\text { (from not important to very important). }\end{array}$ & 2.1 & 10.4 & 25.5 & 34.6 & 27.4 \\
\hline
\end{tabular}

Annex no. 2. Items of the SOC_INFL variable and the distribution of answers

\begin{tabular}{|c|c|c|c|c|c|c|}
\hline \multirow[t]{2}{*}{ Item } & \multirow{2}{*}{$\begin{array}{l}\text { Explanations regarding the item. All items are } \\
\text { scaled up from } 1 \text { to } 5\end{array}$} & \multicolumn{5}{|c|}{ Percentage of response options } \\
\hline & & 1 & 2 & 3 & 4 & 5 \\
\hline FRQ_ENTOUR & $\begin{array}{l}\text { Entourage frequency. How high is the use of } \\
\text { IoT by people around you (friends, } \\
\text { colleagues, relatives)? (from very low } \\
\text { frequency to very high frequency). }\end{array}$ & 7.4 & 28.3 & 40.1 & 20.9 & 3.2 \\
\hline REC_ENTOUR & $\begin{array}{l}\text { Entourage recommendations. How big is the } \\
\text { effect of your entourage's recommendations to } \\
\text { use IoT in tourism? (from very low to very } \\
\text { high). }\end{array}$ & 5.3 & 22.3 & 34.3 & 29.5 & 8.6 \\
\hline PUB_AUTH & $\begin{array}{l}\text { Public authorities. How encouraged do you } \\
\text { think you are in using IoT by public } \\
\text { authorities (community service, relationship } \\
\text { with public institutions, etc.)? (not at all } \\
\text { encouraged to total encouragement) }\end{array}$ & 18.8 & 29.5 & 36.4 & 13.0 & 2.3 \\
\hline
\end{tabular}

Annex no. 3. Items of the HABITS variable and the distribution of answers

\begin{tabular}{|c|c|c|c|c|c|c|}
\hline \multirow[t]{2}{*}{ Item } & \multirow{2}{*}{$\begin{array}{l}\text { Explanations regarding the item. All items are } \\
\text { scaled up from } 1 \text { to } 5\end{array}$} & \multicolumn{5}{|c|}{ Percentage of response options } \\
\hline & & 1 & 2 & 3 & 4 & 5 \\
\hline FRQ_PROF & $\begin{array}{l}\text { Professional IoT frequency. How often do } \\
\text { you consider using IoT in your professional } \\
\text { activities (service tasks)? (from very low } \\
\text { frequency to very high frequency). }\end{array}$ & 17.4 & 23.2 & 32.7 & 21.1 & 5.6 \\
\hline FREE_TIME & $\begin{array}{l}\text { IoT in your free time. How often do you } \\
\text { consider using IoT in other areas of your } \\
\text { activities, in your free time (financial-banking } \\
\text { activities, online shopping, etc.)? (from very } \\
\text { low frequency to very high frequency). }\end{array}$ & 10.0 & 23.0 & 30.6 & 26.2 & 10.2 \\
\hline DIGITAL & $\begin{array}{l}\text { Use of digital technologies. How common are } \\
\text { you to use digital technologies in your general } \\
\text { activities, compared to the national average? } \\
\text { (from very low frequency to very high } \\
\text { frequency). }\end{array}$ & 6.5 & 19.0 & 27.4 & 28.8 & 18.3 \\
\hline
\end{tabular}


Annex no. 4. Items of the PRIV_SAFE variable and the distribution of answers

\begin{tabular}{|c|c|c|c|c|c|c|}
\hline \multirow[t]{2}{*}{ Item } & \multirow{2}{*}{$\begin{array}{l}\text { Explanations regarding the item. All items } \\
\text { are scaled up from } 1 \text { to } 5\end{array}$} & \multicolumn{5}{|c|}{ Percentage of response options } \\
\hline & & 1 & 2 & 3 & 4 & 5 \\
\hline RISK_PRODUCT & $\begin{array}{l}\text { Product risk. How high do you consider the } \\
\text { risk of not benefiting from a product or } \\
\text { service as described? (from very low to } \\
\text { very high). }\end{array}$ & 5.3 & 23.2 & 36.0 & 28.8 & 6.7 \\
\hline PRIV_DATA & $\begin{array}{l}\text { Privacy of data. How high do you consider } \\
\text { the risk that your personal data and those } \\
\text { regarding the chosen product will exceed } \\
\text { the scope of confidentiality? (from very low } \\
\text { to very high). }\end{array}$ & 20.6 & 31.6 & 34.3 & 11.8 & 1.6 \\
\hline RISK_UNSUCC & $\begin{array}{l}\text { Risk of unsuccessful vacation. How worried } \\
\text { are you about the possibility of missing a } \\
\text { vacation due to the choice of a poor quality } \\
\text { tourist product due to the use of IoT } \\
\text { systems? (from not at all worried to very } \\
\text { worried). }\end{array}$ & 13.2 & 27.8 & 33.2 & 20.6 & 5.1 \\
\hline
\end{tabular}

Annex no. 5. Items of the AWARENESS variable and the distribution of answers

\begin{tabular}{|c|c|c|c|c|c|c|}
\hline \multirow[t]{2}{*}{ Item } & \multirow{2}{*}{$\begin{array}{l}\text { Explanations regarding the item. All items are } \\
\text { scaled up from } 1 \text { to } 5\end{array}$} & \multicolumn{5}{|c|}{ Percentage of response options } \\
\hline & & 1 & 2 & 3 & 4 & 5 \\
\hline ADV_IOT & $\begin{array}{l}\text { Awareness of IoT benefits. How well are you } \\
\text { aware of the comparative advantages offered } \\
\text { by IoT systems in relation to the classic } \\
\text { methods of choosing the tourist product or } \\
\text { service? (from very low knowledge to very } \\
\text { high knowledge). }\end{array}$ & 13.2 & 25.5 & 29.9 & 21.6 & 9.7 \\
\hline DISADV_IOT & $\begin{array}{l}\text { Awareness of IoT disadvantages. How well } \\
\text { are you aware of the comparative } \\
\text { disadvantages offered by IoT systems in } \\
\text { relation to the classic methods of choosing the } \\
\text { tourist product or service? (from very low } \\
\text { knowledge to very high knowledge). }\end{array}$ & 19.5 & 30.9 & 28.3 & 16.7 & 4.6 \\
\hline OTHER_EXP & $\begin{array}{l}\text { Knowing the experiences of others. How well } \\
\text { do you know the pleasant or unpleasant } \\
\text { experiences of other tourists in their } \\
\text { relationship with IoT systems? (from very low } \\
\text { knowledge to very high knowledge). }\end{array}$ & 6.7 & 22.3 & 30.2 & 23.7 & 17.2 \\
\hline
\end{tabular}

Annex no. 6. Items of the COST variable and the distribution of answers

\begin{tabular}{|c|c|c|c|c|c|c|}
\hline \multirow[t]{2}{*}{ Item } & \multirow{2}{*}{$\begin{array}{l}\text { Explanations regarding the item. All items are } \\
\text { scaled up from } 1 \text { to } 5\end{array}$} & \multicolumn{5}{|c|}{ Percentage of response options } \\
\hline & & 1 & 2 & 3 & 4 & 5 \\
\hline IMP_PRICE & $\begin{array}{l}\text { The importance of the best price. How } \\
\text { important is it for you to identify the best } \\
\text { price for the tourist product or service? (not at } \\
\text { all important to very important). }\end{array}$ & 0.7 & 5.3 & 22.0 & 28.5 & 43.4 \\
\hline IDENT_PRICE & $\begin{array}{l}\text { Optimal price identification via IoT. How } \\
\text { convinced are you that IoT systems allow you } \\
\text { to identify the best price for the tourist } \\
\text { product or service you are looking for? }\end{array}$ & 7.2 & 20.9 & 29.0 & 30.6 & 12.3 \\
\hline
\end{tabular}

